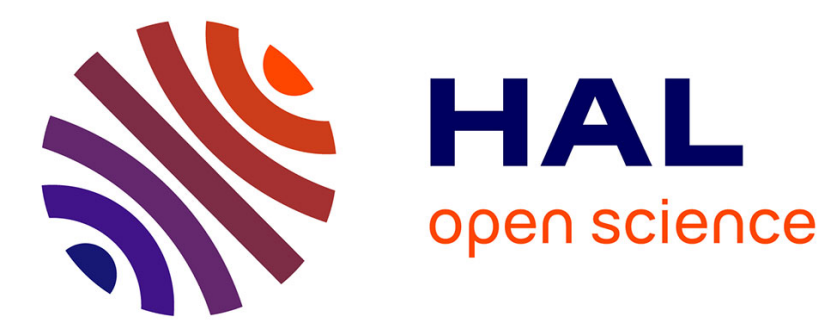

\title{
Ironing out pyoverdine's chromophore structure: serendipity or design?
}

Christine Cézard, Pascal Sonnet, Benjamin Bouvier

\section{To cite this version:}

Christine Cézard, Pascal Sonnet, Benjamin Bouvier. Ironing out pyoverdine's chromophore structure: serendipity or design?. Journal of Biological Inorganic Chemistry, 2019, 24 (5), pp.659-673. 10.1007/s00775-019-01678-x . hal-02395216

\section{HAL Id: hal-02395216 https://hal.science/hal-02395216}

Submitted on 6 Dec 2019

HAL is a multi-disciplinary open access archive for the deposit and dissemination of scientific research documents, whether they are published or not. The documents may come from teaching and research institutions in France or abroad, or from public or private research centers.
L'archive ouverte pluridisciplinaire HAL, est destinée au dépôt et à la diffusion de documents scientifiques de niveau recherche, publiés ou non, émanant des établissements d'enseignement et de recherche français ou étrangers, des laboratoires publics ou privés. 


\title{
Ironing out pyoverdine's chromophore structure: serendipity or design?
}

\author{
Christine Cézard ${ }^{1} \bullet$ Pascal Sonnet ${ }^{1,2} \bullet$ Benjamin Bouvier $* 1$
}

\begin{abstract}
Pyoverdines are Pseudomonas aeruginosa's primary siderophores. These molecules, composed of a fluorescent chromophore attached to a peptide chain of 6 to 14 amino acids, are synthesized by the bacterium to scavenge iron (essential to its survival and growth) from its environment. Hijacking the siderophore pathway to use pyoverdine-antibiotic compounds in a Trojan horse approach has shown promise but remains very challenging because of the synthetic efforts involved. Indeed, both possible approaches (grafting an antibiotic on pyoverdine harvested from Pseudomonas or designing a total synthesis route) are costly, time-consuming and low-yield tasks. Designing comparatively simple analogs featuring the salient properties of the original siderophore is thus crucial for the conception of novel antibiotics to fight bacterial resistance. In this work, we focus on the replacement of the pyoverdine chromophore, a major roadblock on the synthetic pathway. We propose three simpler analogs and evaluate their ability to complex iron and interact with the FpvA transporter using molecular modeling techniques. Based on these results, we discuss the role of the native chromophore's main features (polycyclicity, positive charge, flexibility) on pyoverdine's ability to bind iron and be recognized by membrane transporter FpvA and propose guidelines for the design of effective synthetic siderophores.
\end{abstract}

Keywords Pseudomonas aeruginosa, siderophore, in silico, drug design, antibiotics, chemical biology.

Christine Cézard and Benjamin Bouvier contributed equally to this work.

Electronic Supplementary Information (ESM): computational details, detailed B3LYP and M06 results, frontier orbital representations, detailed molecular dynamics results.

Benjamin Bouvier

benjamin.bouvier@u-picardie.fr

${ }^{1}$ Laboratoire de Glycochimie, des Antimicrobiens et des Agroressources (LG2A), UMR 7378 CNRS/Université de Picardie Jules Verne - 10, rue Baudelocque, 80089 Amiens Cedex, France.

${ }^{2}$ Agents Infectieux, Résistance et Chimiothérapie (AGIR), EA 4294 Université de Picardie Jules Verne - 1, rue des Louvels, 80037 Amiens Cedex 1, France.

\section{Introduction}

Pseudomonas aeruginosa, a Gram-negative bacterium, is an opportunistic pathogen infecting humans with compromised immune defense causing chronic and/or life-threatening infections. It is the third most common Gram-negative pathogen causing bactaeremia and exhibits documented resistance to numerous antibiotics such as $\beta$-lactams, carbapenems, aminoglycosides, and fluoroquinolones.[1-3] The World Health Organization, which has recently elevated antimicrobial resistance to crisis level[4], has placed $P$. aeruginosa on the top tier for priority. Developing novel strategies to overcome acquired resistance to antibiotics in $P$. aeruginosa and other such "superbugs" has thus become a global public health concern. The fact that a single new class of anti-infectives (oxazolidinones) has emerged on the market in the last two decades[5] is a good indicator of the criticality of the situation. Fortunately, academic and fundamental research focused on deciphering host-pathogen interactions is intensifying and some approaches show promising outcomes in the fight against superbugs.[6] Examples include (i) developing peptides to specifically inhibit bacterial biofilm formation, $[7,8]$ (ii) bypassing the low permeability of the bacterial outer membrane, (iii) inhibiting the active efflux system in charge of expelling small molecules such as antibiotics,[9-11] (iv) hindering drug inactivation and modification by bacterial enzymes[12] and (v) hijacking or inhibiting the bacterial metal acquisition system.[13] In this work, we focus on the latter and specifically scrutinize the interaction between $\mathrm{Fe}^{3+}$ and pyoverdine, the primary siderophore of $P$. aeruginosa.

The growth and survival of $P$. aeruginosa requires iron, which is scarce in an aerobic environment due to the low solubility of its ionic forms at circumneutral $\mathrm{pH}$ and host-bound in the context of an infection. Hence, a competition for iron between host and bacteria takes place and often represents a prequel to virulence. In order to efficiently scavenge iron from the host, bacteria have developed siderophores: these low molecularweight iron chelators, produced under iron-starved conditions, possess a very high affinity for $\mathrm{Fe}^{3+}$ ions. Once loaded with iron, the metal-siderophore complexes are recognized by specific bacterial outer membrane transporters, which translocate them into the periplasm using energy-dependent active transport mechanisms.

$P$. aeruginosa produces siderophores pyoverdine and pyochelin, whose respective specific outer membrane receptors are FpvA and FptA. It has been recently demonstrated that $P$. aeruginosa synthesizes pyochelin first but switches to pyoverdine when the concentration in iron becomes low, most likely because producing pyoverdine is more energyconsuming.[14] Not only does pyoverdine present a much higher affinity for $\mathrm{Fe}^{3+}$ than pyochelin $\left(\log \mathrm{K}_{\mathrm{f}}\left(\mathrm{Fe}^{\mathrm{III}}\right)=30.8\right.$ vs $17.2[15]$ and $\mathrm{pFe} \mathrm{e}^{\mathrm{III}}=27$ vs. 16), but it is also produced in much larger amounts (at least 10-fold more).[16, 17] Besides, it has been shown that the FpvA transporter is not exclusively specific to its cognate pyoverdine but is able to transport pyoverdines from other Pseudomonas strains as well.[18] Even more strikingly, this transporter has recently been shown to internalize pyocins (bacterial proteins designed to inhibit the growth of competing strains), which are able to masquerade as 
pyoverdines despite their much larger size.[19] Following this train of thought, designing pyoverdine analogs to flood the bacterial environment could (i) fool $P$. aeruginosa out of its energy economy mode, exposing it to attacks and (ii) bring it "gifts", in the form of siderophore-grafted antibiotic moieties. The efficiency of this Trojan horse strategy in the context of siderophores is amply demonstrated by nature: albomycins, ferrimycins and salimycins are natural antibiotics produced by streptomycetes which combine a metal chelator (resp. partial ferrichrome, ferrioxamine $B$ and tris-hydroxamate) and a toxic molecule via a linker (resp. serine, amide and dicarboxylic acid).[20] Emulating this approach, antibiotics grafted to synthetic mixed hydroxamate/catecholate siderophores have been shown since the early 1990's to be internalized by several bacterial membrane transporters [21] and to negatively impact bacterial growth.[22] The use of pyoverdine in drug delivery strategies (reviewed by Mislin et al[23]) was pioneered by Budzikiewicz et al.[24]: these researchers grafted ampicillin onto the amino groups of basic amino acids on the peptide chain of pyoverdines from ATCC27853 and ATCC13525 strains, in the hope that the siderophore moieties could provide a novel point of entry for the antibiotic into the periplasm of ampicillinresistant bacteria. Indeed, the compounds displayed high level of antibiotic activity, overcoming the bacteria's resistance. In the wake of this pioneering work, the same authors grafted the antibiotic cephalexin to the arginine side chain of ATCC15692. The resulting compound triggered an increase in iron uptake, proving its successful ingress into the periplasm, but showed no antibiotic activity.[25] This is likely due to the bulk of the grafted siderophore sterically inhibiting the recognition of the antibiotic moiety, and could potentially be solved using easily cleavable antibiotic-siderophore linkers; however, such fragile connections have been shown to severely limit the activity of Trojan-horse compounds when going from in vitro to in vivo.[26] Indeed, the in vivo evaluation of the activity of Trojanhorse compounds raises the difficulty to another level entirely, for several reasons. First is the lack of animal models mimicking human situations; recent efforts in this direction[27] do not yet include $P$. aeruginosa. Second, the impact of mature biofilms predating drug administration is problematic to evaluate, since the connection between iron acquisition and biofilm formation/preservation is far from clearly understood and standardized experimental conditions for effective testing have yet to be defined.[28] Finally, unexpected evasive tactics by bacteria can hinder potentially effective therapies: for instance, $P$. aeruginosa can evolve in-host to acquire iron from hemoglobin upon loss of pyoverdine production or functionality.[29]

These issues highlight a major pitfall of the Trojan horse approach: the hybrid compounds being more than the sum of their parts, one part can negatively impact the recognition of the other. Since these detrimental collective effects are expected to be mainly steric in nature, designing smaller and simpler analogs of both the siderophore and antibiotic moieties appears a worthwhile strategy to limit such issues. Reducing the siderophore's size and chemical complexity has the added incentive of making it more amenable to chemical synthesis.
However, a rational simplification of the siderophore scaffold can only be carried out with a sufficient understanding of the role of pyoverdine's structural motifs on the corresponding bacterial pathways, which is still very limited as of now.[20, 30] Indeed, while the discovery of pyoverdine (via its fluorescence properties) dates back to the end of the $19^{\text {th }}$ century, [31] its complete structure hasn't been published until 1981.[32] Today, more than 100 pyoverdines, produced by different strains and species of Pseudomonas, have been identified.[33, 34] While structurally different, these siderophores possess common features: (i) a conserved chromophore binds $\mathrm{Fe}^{3+}$ via a catecholate function; (ii) a peptidic moiety (linear or cyclic) composed of 6 to 14 amino acids interacts with $\mathrm{Fe}^{3+}$ via two hydroxamate and/or carboxylate functions and (iii) a strain- and growth condition-dependent acyl side-chain, whose purpose remains elusive, is attached to the chromophore. In a strategy to develop pyoverdine mimics with the tools of total organic synthesis, the chromophore ((1S)-5-amino-2,3-dihydro-8,9dihydroxy-1H-pyrimido-[1,2-a]quinoline-1-carboxylic acid) is the most challenging residue to synthesize, in no small part due to its delocalized positive charge and triple ring framework. In this work, we postulate that a catechol-like moiety, with a similar backbone but lacking either the positive charge or some of the rings, might act as a simple and convenient replacement - or at least help pinpoint the roles of these features in the interaction of pyoverdine with $\mathrm{Fe}^{3+}$ and the FpvA transporter, which would be invaluable for the rational design of antibiotics based on the pyoverdine scaffold. Herein, we apply molecular modeling methods ( $a b$ initio, molecular dynamics and docking) to the preliminary assessment of the validity of this strategy. We build on the expertise of our group which has, in the past few years, palliated the dearth of computational studies on bacterial siderophores by combining quantum chemistry, forcefield design and state-of-the art free energy simulations to study the structural properties of pyoverdines and their impact on recognition by the FpvA transporter[35, 36], and experimented with simple tris-catecholate ligands showing promising ironbinding affinities.[37] In this paper, we follow a stepwise approach: (i) we extract the individual iron chelation capabilities of catecholate and hydroxamate moieties, (ii) investigate possible synergistic effects in the metal-binding affinities of model monocatecholate-bis-hydroxamate systems, (iii) check the influence of the peptide chain linking the chelating groups in pyoverdine analogs built thereupon and (iv) study the interaction of these analogs with the FpvA transporter. We expect each step of the way to provide insights for the design of simple yet functional mimics of the pyoverdine PAO1 chromophore able to chelate $\mathrm{Fe}^{3+}$ and be transported through FpvA for therapeutic purposes.

\section{Methods}

For brevity, only the essential features of the computational pipeline employed are reported below. The full computational details for each method are provided in ESM.

System preparation. The starting geometry for the reference pyoverdine Pvdl (Fig. 1b) was taken from Protein Data Bank 
entry $2 \mathrm{~W} 16$, in which the pyoverdine is bound to its cognate FpvA transporter.[18]

Spin states of siderophore-bound $\mathrm{Fe}^{3+}$. In ab initio calculations, $\left[\mathrm{Fe}^{3+} \mathrm{L}_{6}\right]$ complexes were treated as high spin, open shell systems featuring a ferric ion with five unpaired electrons $(S=5 / 2)$ and a multiplicity of six; spin crossover was neglected (see ESM for justifications).

Density functional theory (DFT) calculations. Among the numerous functionals tested on open-shell $\mathrm{Fe}^{3+}$ systems in the past decade, the hybrid B3LYP[38-40] and M06[41, 42] functionals tend to provide the most consistent results when multiple quantities (structure, properties, energetics, reactivity...) are evaluated simultaneously.[43-45]. The 6-31G* basis set, a verified compromise[46-49] between accuracy and computational cost in these systems, was used. B3LYP and M06 were found to provide similar results on our systems (RMSD $<0.3$ $\AA$ and $\mathrm{Fe}^{3+}-\mathrm{O}$ distances within $0.03 \AA$ for optimized structures, $2 \%$ difference in binding energies). Hence, only the B3LYP results are presented below, and the M06 results can be found in ESM.

$\boldsymbol{A} \boldsymbol{b}$ initio binding energies. Binding energy was defined as the difference between the calculated energy of the complex and the sum of that of its isolated partners: $E_{\text {binding }}=E_{\text {complex }}-\left(E_{\mathrm{Fe} 3+}+\right.$ $\left.\sum E_{\text {ligand }}\right)$. For homogeneous complexes $\left(\mathrm{Fe}^{3+}-\mathrm{L}_{3}\right)$ and neglecting collective effects, the per-ligand binding energies were estimated as follows: $E_{\text {per_ligand }}=E_{\text {binding }} / 3$. All binding energies were obtained on optimized geometries of the complexes and isolated cation and ligands. Basis set superposition errors (BSSE), which can reach $8 \%$ of binding energies in similar systems, $[50,51]$ were systematically corrected.

Additional $\boldsymbol{a} \boldsymbol{b}$ initio calculations. Zero-point, thermal and entropic corrections were added to the electronic energies to calculate gas-phase Gibbs free energies. The quantum theory of atoms in molecules[52, 53] (QTAIM) was used for the topological analysis of bond critical points $(\mathrm{BCP})$ in the electron density at Fe... bond paths.

Molecular Dynamics (MD) Simulations. The AMBER99SB force field[54] was used for standard aminoacids. Nonconventional residues (chromophores and analogs, ornithine, side-chainbranching lysine) required additional parameterization, which was achieved as described in our previous work. [35-37] In order to monitor the capacity of the different siderophores to bind and retain $\mathrm{Fe}^{3+}$, iron was treated noncovalently using the nonbonded parameters of Giammona.[55] The systems were solvated in a truncated octahedral TIP3P water box with a buffer distance of $10 \AA$ and neutralized with a minimal number of $\mathrm{Na}^{+}$ or $\mathrm{Cl}^{-}$ions.

After a typical equilibration procedure (see ESM), MD simulations were performed at constant pressure of 1 bar and temperature of $300 \mathrm{~K}$ using periodic boundary conditions and PME long-range electrostatics.[56] Solvation free energies were computed using the MM-GBSA method. The conformational space explored using molecular dynamics simulations was clustered with the hierarchical agglomerative approach; the central structure of each cluster was minimized $a b$ initio and the most stable candidate was retained.
Docking. Docking calculations of (partially flexible) pyoverdine$\mathrm{Fe}^{3+}$ complexes onto the (rigid) FpvA transporter explored the volume defined by a cube with an edge length of $60 \AA$ and centered on the experimental binding site.

(a)

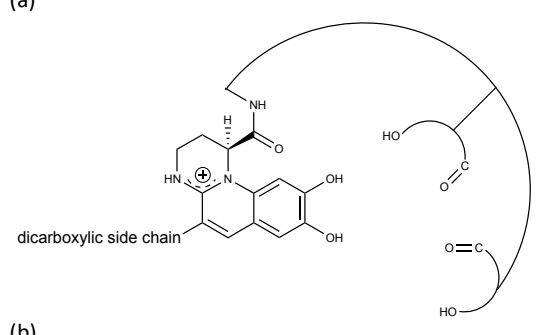

(b)

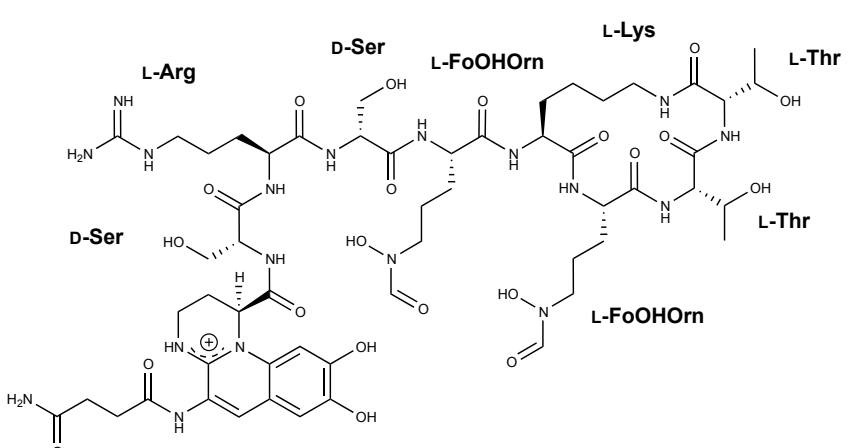

Fig. 1 (a) General pyoverdine structure. (b) Structure of Pvdl from P. aeruginosa strain ATCC 15692.

\section{Results}

Pyoverdine analogs. Pyoverdine ATCC15692, produced by strains of $P$. aeruginosa PAO1 (Fig. 1b), is the archetype of the pyoverdine family, whose $100+$ members comply with the general scaffold shown on Fig. 1a. It will be referred to as Pvdl in the remainder of the text. Its partially cyclic peptide moiety is composed of eight amino acids, two of which are in a D configuration and two non-natural (hydroxy-formyl-ornithine). The chelation of $\mathrm{Fe}^{3+}$ is performed by the chromophore and the two ornithines, all nonsymmetrical bidentate ligands. The trischelate $\mathrm{Fe}^{3+}$-Pvdl complex thus formed presents a metallic center with an octahedral geometry. The arrangement of the three ligands around the cation can lead to many enantiomers which can be classified by the sense of the screw axis defined by the six donor atoms: left-handed helices are assigned the $\Lambda$ configuration, while right-handed helices belong to the $\Delta$ configuration.[57] Pyoverdines known to be internalized by the FpvA transporter tend to present the following characteristics:[18] (i) the peptidic sequence starts with a Dserine, (ii) the second amino acid is basic, (iii) the third residue is small, (iv) the first iron chelating amino acid is in the fourth position of the peptide sequence, (iv) the peptide sequence is partially cyclic, ( $v$ ) the metal center is in a $\Lambda$ configuration.

Because of the complexity of the chromophore and nonproteinogenic amino acids, very few synthetic routes towards pyoverdine have been proposed (including a single successful attempt at total synthesis[58]) and the endeavor remains challenging. In particular, the construction of the fused tricyclic 
chromophore skeleton and the correct introduction of the double bond on the second chromophore ring require multiple steps, lowering yields and increasing costs. Triggered by the renewed interest for siderophore-based therapeutics in the context of accrued bacterial resistance, novel synthetic routes are currently being explored;[59] however, there remains a strong incentive for the rational simplification of the chromophore scaffold based on the understanding of its features. To this purpose, we designed three replacements units (namely CR1, CR2 and CR3) for the original chromophore CRO (Fig. 2). All three retain the catechol functions, but reduce the number of rings to one or two and discard the positive charge of the chromophore and the chiral center at atom C1. In all three, the third ring is replaced by a glycine, whose nitrogen atom is positioned to replace either N12 (CR1, CR2) or N4 (CR3). $\mathrm{CR} 1$ and $\mathrm{CR} 2$ retain the substituent group at $\mathrm{C} 5$ but differ in their intrinsic rigidities via an optional second cycle; CR3 employs an amide function to simultaneously emulate the rigidity of the second cycle and the polar nature of the $\mathrm{C} 5$ substituent. CR2 has a chiral center whose configuration was not found to affect any of the results presented herein (see ESM for details). We subsequently introduce pyoverdine analogs aPvd1, aPvd2 and aPvd3, respectively built upon chromophore analogs CR1, CR2 and CR3 and the peptide chain of Pvdl. (a)<smiles>[R]NC1=Cc2cc(O)c(O)cc2N2C(=O)N=CC[C@@H]1C2C(=O)O</smiles>
(c)<smiles>[R]N[C@H]1Cc2cc(O)c(O)cc2N(CC(=O)[OH2+])C1</smiles>

(b)<smiles>[R]NCCc1cc(O)c(O)cc1NCC(=O)O</smiles>

(d)<smiles>O=C(O)CNC(=O)Cc1ccc(O)c(O)c1</smiles>

Fig. 2 Structure of the native chromophore CRO of Pvdl (a) and the three analogs under study: CR1 (b), CR2 (c), CR3 (d).

Model systems. Pyoverdines bind iron though three bidendate functions, one catecholate and two hydroxamates. As such, they appear to represent a middle ground between enterobactin, the primary siderophore of $E$. coli which interacts with $\mathrm{Fe}^{3+}$ via three catecholate functions and is one of the most efficient natural binders of ferric ions known to date ( $\mathrm{pFe} \mathrm{e}^{\mathrm{III}}=$ 35.5, $\left.\log \mathrm{K}_{\mathrm{f}}\left(\mathrm{Fe}^{\mathrm{III}}\right)=49\right)[60]$, and desferrioxamine $\mathrm{B}$, siderophore of Streptomyces, which employs three hydroxamate functions and shows a lesser affinity for iron $\left(p F e^{I I I}=26.6, \log K_{f}\left(F^{I I I \prime}\right)=\right.$ 31).[61] To rank of the complexing abilities of the hydroxamate and catecholate ligands and compare the pyoverdine- $\mathrm{Fe}^{3+}$ interactions to simple references, we have built simple triscatecholate $\left(\mathrm{Fe}^{3+}\left(\mathrm{Cat}^{2-}\right)_{3}\right)$, tris-hydroxamate $\left(\mathrm{Fe}^{3+}\left(\mathrm{Aha}^{-}\right)_{3}\right)$ and pyoverdine-like $\left(\mathrm{Fe}^{3+}\left(\mathrm{Cat}^{2-}\right)\left(\mathrm{Aha}^{-}\right)_{2}\right)$ model systems (Fig. 3). Furthermore, to gain insight into the role of the chromophore and its analogs, we have replaced the catechol motif in these model systems by CR0, CR1, CR2 or CR3, yielding model systems
$\mathrm{Fe}^{3+}\left(\mathrm{CRO}^{-}\right)_{3}, \quad \mathrm{Fe}^{3+}\left(\mathrm{CR}^{2-}\right)_{3}, \mathrm{Fe}^{3+}\left(\mathrm{CR}^{2-}\right)_{3}, \mathrm{Fe}^{3+}\left(\mathrm{CR}^{2-}\right)_{3}, \mathrm{Fe}^{3+}\left(\mathrm{CRO}^{-}\right.$ )$\left(\mathrm{Aha}^{-}\right)_{2}, \mathrm{Fe}^{3+}\left(\mathrm{CR}^{2-}\right)\left(\mathrm{Aha}^{-}\right)_{2}, \mathrm{Fe}^{3+}\left(\mathrm{CR}^{2-}\right)\left(\mathrm{Aha}^{-}\right)_{2}$ and $\mathrm{Fe}^{3+}\left(\mathrm{CR}^{2-}\right.$ )(Aha- $)_{2}$. The Aha- ligand being nonsymmetrical, many conformations of the $\mathrm{Fe}^{3+}\left(\mathrm{Aha}^{-}\right)_{3}$ complex can theoretically being formed; we have limited ourselves to the configuration presenting a pseudo- $C_{3}$ symmetry. For the remaining $\mathrm{Fe}^{3+}(\mathrm{X})\left(\mathrm{Aha}^{-}\right)_{2}$ model systems, the orientation of the Aha- units was kept identical to Pvdl. The original exocyclic architecture of the $\mathrm{Fe}^{3+}-\mathrm{Pvdl}$ complexation center were kept, and all complexes are in their $\Lambda$ configuration.

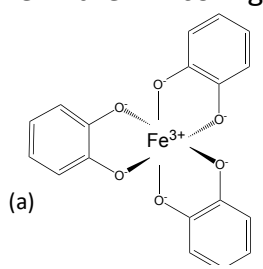

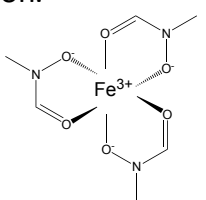

(b)

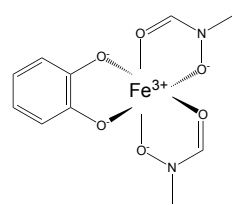

(c)
Fig. 3 Structures of model tris-catecholate (a), tris-hydroxamate (b) and pyoverdine-like monocatecholate-bis-hydroxamate (c) systems binding $\mathrm{Fe}^{3+}$.

Iron-binding properties. The efficacy of pyoverdine derivatives as siderophores can be evaluated from their $\mathrm{Fe}^{3+}$-binding properties. To this end, $a b$ initio calculations were performed on the most stable structures of all analogs and model systems. The effects of conformational flexibility and solvation on the binding of iron were explored with 50 ns of MD simulations coupled with MM-GBSA calculations.

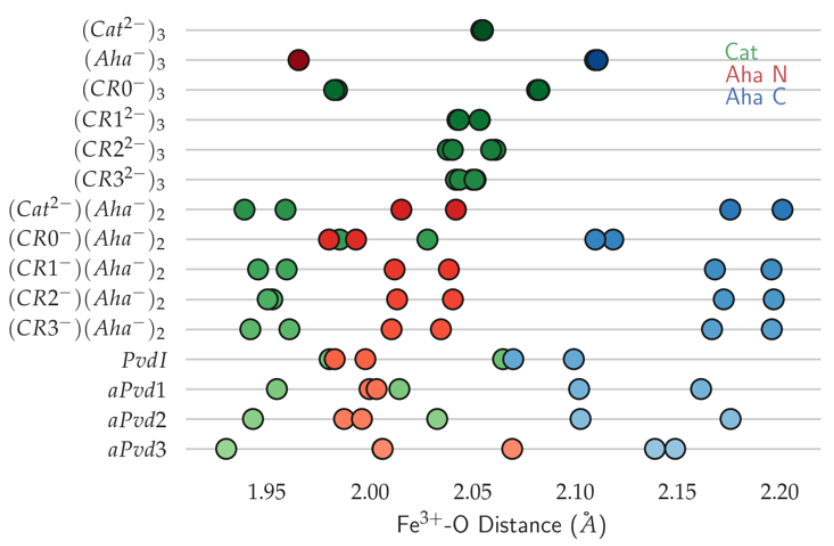

Fig. $4 \mathrm{Fe}^{3+\cdots O} \mathrm{O}$ distances in pyoverdine and analogs, colored by oxygen type.

The $a b$ initio $\mathrm{Fe}^{3+\ldots O} \mathrm{O}$ distances for every complex (Fig. 4) fall within a $1.93-2.20 \AA$ range indicating a strongly coordinated interaction between the three bidentate ligands and the ferric ion. The distances reported for the tris-catecholate complex are close to those obtained by X-Ray analysis[62], validating the methodology on other systems for which no such experimental data is available.

All tris-catecholate systems $\left(\mathrm{Fe}^{3+}\left(\mathrm{Cat}^{2-}\right)_{3}, \mathrm{Fe}^{3+}\left(\mathrm{CRO}^{-}\right)_{3}, \mathrm{Fe}^{3+}\left(\mathrm{CR}^{2-}\right.\right.$ )$_{3}, \mathrm{Fe}^{3+}\left(\mathrm{CR}^{2-}\right)_{3}$ and $\left.\mathrm{Fe}^{3+}\left(\mathrm{CR}^{2-}\right)_{3}\right)$ adopt the expected $\mathrm{C}_{3}$ symmetry. However, unlike the other systems, each ligand in $\mathrm{Fe}^{3+}(\mathrm{CRO}-)_{3}$ features two strikingly non-identical $\mathrm{Fe}^{3+\ldots \mathrm{O}}$ distances. Interestingly, distances in $\mathrm{Fe}^{3+}\left(\mathrm{CRO}^{-}\right)_{3}$ are comparable to those encountered in $\mathrm{Fe}^{3+}\left(\mathrm{Aha}^{-}\right)_{3}$, in which the $\mathrm{Fe}^{3+\ldots \mathrm{O}=\mathrm{C}}$

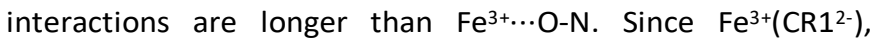
$\mathrm{Fe}^{3+}\left(\mathrm{CR}^{2-}\right)$ and $\mathrm{Fe}^{3+}\left(\mathrm{CR}^{2-}\right)$ do not exhibit this behavior, it is most likely due to the presence of the additional positive charge 

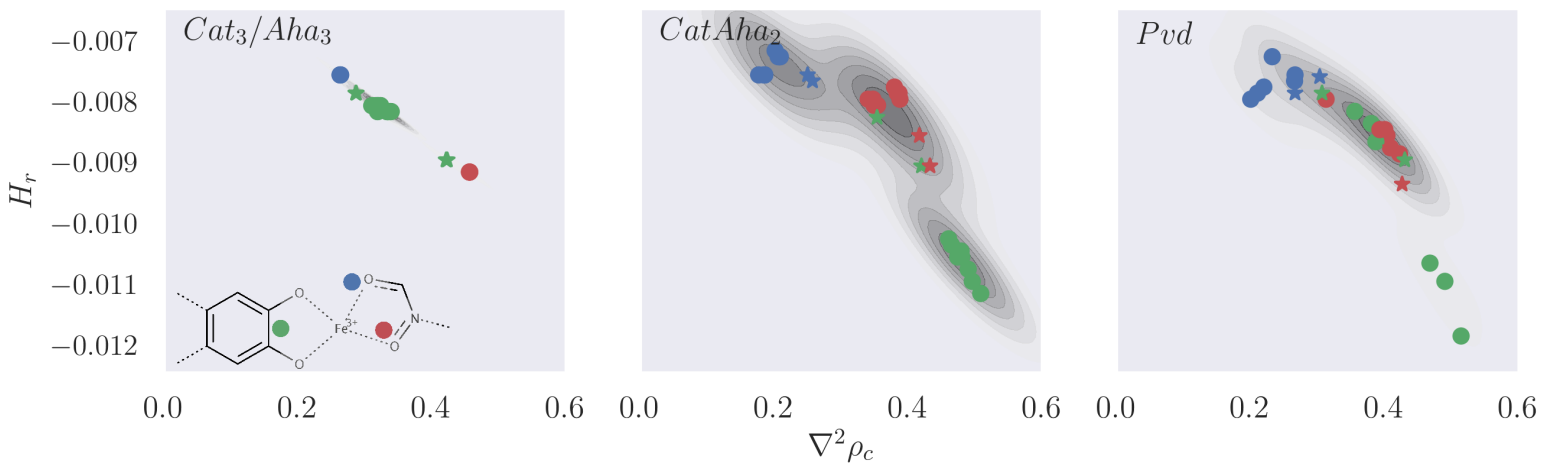

Fig. 5 Covalent/ionic character of the $\mathrm{Fe}^{3+\ldots O}$ interactions in (left) tris-catecholate/tris-hydroxamate model systems; (center) monocatecholate-bis-hydroxamate model systems; (right) Pvdl and analogs, as defined by the Laplacian of the electron density $\nabla^{2} \rho$ and the energy density Hr at the BCP. Stars identify the interactions made by the native catecholate chromophore of Pvdl (CRO).

on the third chromophore ring rather than to the asymmetry of the chromophore analogs compared to catechol. These observations apply to mixed hydroxamate/catecholate model systems as well. As a general principle, the replacement of catecholates by hydroxamates eases the steric hindrance and alleviates the electronic repulsion brought about by the former's bulk and -2 net charge, resulting in $\mathrm{Fe}^{3+\ldots} \mathrm{O}$ interactions that are shorter for the remaining catecholate and longer for the hydroxamates. However, as for the tris-catecholates, $\mathrm{Fe}^{3+\ldots} \mathrm{O}$ interactions within a catecholate ligand remain grossly equivalent in all models except $\mathrm{Fe}^{3+}\left(\mathrm{CRO}^{-}\right)\left(\mathrm{Aha}^{-}\right)_{2}$.

The conformational strain induced by the peptide chain results in nonequivalent $\mathrm{O} \cdots \mathrm{Fe}^{3+}$ distances within catecholate moieties for Pvdl and all its analogs aPvd1-3. However, in Pvdl, the catecholate and hydroxamate $\mathrm{Fe}^{3+\ldots O}$ distances are a nearperfect match, resulting in a pseudo- $C_{3}$ arrangement of the ligands around the metal ion despite their different natures; conversely, in the analogs, the catecholate $\mathrm{Fe}^{3+\ldots O}$ distances are consistently shorter than their hydroxamate counterparts just like in the monocatecholate-bis-hydroxamate model systems.

To correlate these structural results with the relative nature and strengths of individual $\mathrm{Fe}^{3+\ldots O}$ interactions, topological analyses of bond critical points (BCP) were performed. The Laplacian $\nabla^{2} \rho$ of the electron density $\rho$ at the BCP reveals the balance of ionic and covalent characters for the bond: larger (resp. smaller) values denote a marked covalent (resp. ionic) character.[53] A complementary information can be extracted from the energy density $\mathrm{Hr}$, which can be decomposed into the sum of a repulsive kinetic term $\mathrm{Gc}$ and an attractive potential term Vc: the latter tends to dominate interactions of marked covalent character, yielding negative $\mathrm{Hr}$ values. All systems under study feature negative (albeit small) $\mathrm{Hr}$ values at the $\mathrm{BCP}$, confirming the partly covalent character of $\mathrm{Fe}^{3+\ldots O}$ interactions (Fig. 5).

The specificity of $\mathrm{Fe}^{3+}\left(\mathrm{CRO}^{-}\right)_{3}$ among tris-catecholate systems again becomes apparent: while the latter feature six equivalent $\mathrm{Fe}^{3+\ldots O}$ bonds characterized by interchangeable $\left(\nabla^{2} \rho, \mathrm{Hr}\right)$ values, the former shows a clear split in the nature of the two iron-oxygen interactions of each ligand (Fig 5, left panel). The circulation of the additional positive charge borne by CRO- drives one iron-oxygen interaction towards a more covalent behavior (larger absolute values of $\mathrm{H}_{\mathrm{r}}$ and smaller $\nabla^{2} \rho$ ) while the other becomes weaker and more ionic. Intriguingly, from the standpoint of $\mathrm{BCP}, \mathrm{Fe}^{3+}\left(\mathrm{CRO}^{-}\right)_{3}$ is very close to $\mathrm{Fe}^{3+}\left(\mathrm{Aha}^{-}\right)_{3}$, in which the nitrogen-bound oxygen of each ligand forms a much more covalent bond to $\mathrm{Fe}^{3+}$ than its carbon-bound counterpart. Replacing catecholates with hydroxamates tends to strengthen catecholate- $\mathrm{Fe}^{3+}$ and weaken hydroxamate- $\mathrm{Fe}^{3+}$ interactions compared to the tris-systems (Fig. 5, center panel); the weakening of the hydroxamate $\mathrm{Fe}^{3+\ldots} \mathrm{O}-\mathrm{N}$ bond brings it closer to its more ionic $\mathrm{Fe}^{3+\ldots} \mathrm{O}-\mathrm{C}$ counterpart. Again, $\mathrm{Fe}^{3+}\left(\mathrm{CRO}^{-}\right)\left(\mathrm{Aha}^{-}\right)_{2}$ is an exception to this rule: with comparatively strong hydroxamate and weak catecholate interactions to $\mathrm{Fe}^{3+}$, it is once again closer to $\mathrm{Fe}^{3+}\left(\mathrm{Aha}^{-}\right)_{3}$ than to $\mathrm{Fe}^{3+}\left(\mathrm{Cat}^{2-}\right)\left(\mathrm{Aha}^{-}\right)_{2}$.

The presence of the peptide chain in Pvdl and its aPvd analogs (Fig. 6, right panel) has much more impact on the interaction of $\mathrm{Fe}^{3+}$ with the catecholates than with the hydroxamates. While the flexible hydroxamates can adopt an optimal arrangement around $\mathrm{Fe}^{3+}$ despite the constraints introduced by the cyclic peptide chain, the distal chelating oxygen of the more rigid catecholates is pulled away from the metal center, weakening the corresponding interaction. Yet again, the BCP character of $\mathrm{Fe}^{3+}-\mathrm{Pvdl}$ is comparable to that of $\mathrm{Fe}^{3+}\left(\mathrm{Aha}^{-}\right)_{3}$, while $\mathrm{Fe}^{3+}$-aPvd mimics $\mathrm{Fe}^{3+}\left(\mathrm{Cat}^{2-}\right)\left(\mathrm{Aha}^{-}\right)_{2}$. Pvdl is remarkable in its ability to equalize the metal chelating properties of ligands of very different chemical natures, possibly to achieve a tradeoff between affinity for the metal ion and preservation of enough structural complexity to ensure other functions (recognition by transporters...).
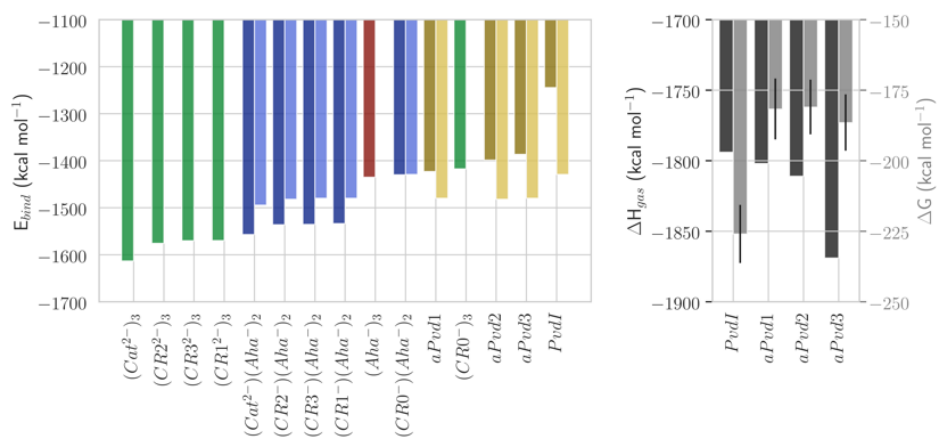

Fig. 6 Left: $a b$ initio $\mathrm{Fe}^{3+}$-binding energies of tris-catecholates (green), trishydroxamate (red), monocatecholate-bis-hydroxamates (blue) and pyoverdine 
analogs (yellow). Lighter bars represent binding energies calculated as the sum of individual ligand binding energies. Right: MM-GBSA Fe ${ }^{3+-}$-binding enthalpy in the gas phase (black bars, left axis) and $\mathrm{Fe}^{3+}$-binding free energies (grey bars with errorbars, right axis) of pyoverdine and analogs.

A similar picture emerges from the $\mathrm{Fe}^{3+}$ interaction energies (Fig. 6). Tris-catecholates bind $\mathrm{Fe}^{3+}$ more strongly than trishydroxamates, with the notable exception of native chromophore CRO- which again tends to behaves more like the latter than the former. As expected, monocatecholate-bishydroxamates represent a middle ground. In fact, if one evaluates the individual interaction energies of the catecholate and hydroxamate groups as the third of the interaction energies of the tris-complexes and sum their contributions in the monocatecholate-bis-hydroxamates, the correct interaction energies can be predicted within a $4 \%$ error margin: collective effects (which tend to stabilize the complexes) thus appear quite limited. In pyoverdine analogs, the deviation from the sum of individual ligand binding energies is larger and in the opposite direction: the conformational strain induced by the peptide chain results in unfavorable collective effects. Surprisingly, these are much more strongly marked for the native pyoverdine than for its analogs, corroborated by gas-phase binding enthalpy values obtained from MM-GBSA calculations (Fig. 5, right panel) in which Pvdl appears less strongly bound than the latter. A look at the frontier molecular orbitals (see ESM) reveals that the lowest unoccupied molecular orbital (LUMO) and the highest occupied molecular orbital (HOMO) of $\mathrm{Fe}^{3+-a P v d}$ systems are localized on the metal ion and the chromophore, respectively, which is indicative of a charge transfer from chromophore to metal. This behavior, also seen in $\mathrm{Fe}^{3+}\left(\mathrm{Cat}^{2-}\right)_{3}$, is in agreement with previous studies of related systems.[50, 51] On the other hand, $\mathrm{Fe}^{3+}-\mathrm{Pvdl}$ frontier orbitals are much more complex and involve the metal ion and its three ligands simultaneously, as in $\mathrm{Fe}^{3+}\left(\mathrm{Aha}^{-}\right)_{3}$. The hydroxamates which play a role in the HOMO and LUMO of $\mathrm{Fe}^{3+}-\mathrm{Pvdl}$ do not contribute to either frontier orbital of $\mathrm{Fe}^{3+}$-aPvd. The larger HOMO-LUMO gap in $\mathrm{Fe}^{3+}-\mathrm{Pvdl}$ compared to $\mathrm{Fe}^{3+}-$ aPvd (similar to that of $\mathrm{Fe}^{3+}\left(\mathrm{Aha}^{-}\right)_{3}$ vs $\left.\mathrm{Fe}^{3+}\left(\mathrm{Cat}^{2-}\right)_{3}\right)$ confirms the lower $\mathrm{Fe}^{3+}$ binding affinity of Pvdl; it also provides yet another confirmation of the remarkable similitude of $\mathrm{Pvdl}$ and $\left(\mathrm{Aha}^{-}\right)_{3}$ for the complexation of $\mathrm{Fe}^{3+}$.
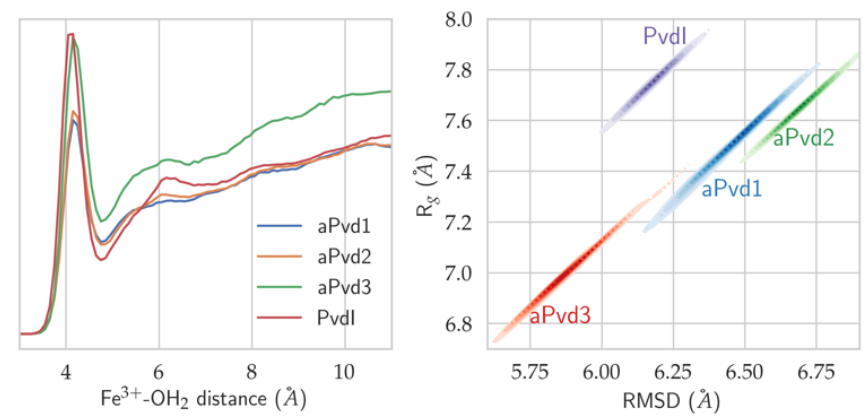

Fig. 7 Radial distribution functions of water molecules around (left) and kernel density estimations of (RMSD, radius of gyration) pairs for (right) Pvdl and analogs.

Intriguingly, upon solvation, stabilities are reversed and Pvdl becomes the strongest binder by $40-50 \mathrm{kcal} \mathrm{mol}^{-1}$, in agreement with the pFe values measured in our previous work[37] and hinting at particularly favorable interactions with water; however, as we will see below, the binding affinities of the analogs remain well within the range of efficient siderophores.

Conformational dynamics of the siderophores. We now focus on the influence of the conformational dynamics of the siderophores and neighboring water on $\mathrm{Fe}^{3+}$ binding. The radial diffusion functions ( $\mathrm{rdf}$ ) of water around the metal cation are represented on Fig. 7 left panel. The first peak's remote position (>4 Å) and small width hint at a strongly structured first water layer, but which cannot penetrate the metal's first coordination sphere. Pvdl shows a remarkable long-distance structuration of water, with clearly visible second- and third-layer peaks, which could explain the added stability of solvated $\mathrm{Fe}^{3+}-\mathrm{Pvdl}$ seen earlier. aPvd3 also achieves a similar long-range ordering of water, whereas aPvd1 and aPvd2 have almost no impact on water molecules beyond their (rather sparse) first hydration layer. Regarding the stability difference between $\mathrm{Fe}^{3+}-\mathrm{Pvdl}$ and $\mathrm{Fe}^{3+}-\mathrm{aPvd} 3$ in water, it appears that the entropic penalty associated with the ordering of multiple water layers is obviously not as well compensated by favorable interactions with water in the latter compared to the former; this could be due to the additional hydrogen-bonding functions on the chromophore substituent chain at C5.

The distributions of RMSD to the average structure and radius of gyration $(\mathrm{Rg})$ indicate relatively rigid and compact structures for all systems under study (Fig. 7, right panel). Pvdl-Fe ${ }^{3+}$, the bulkiest of all siderophores studied herein, features contained RMSDs and a compact distribution of radii of gyration ( $\mathrm{Rg}$ ), indicative of an enhanced conformational stability both at the local and global levels. Despite sharing $\mathrm{CRO}^{-\triangleleft} \mathrm{s}$ bond pathway to Ser3, CR12- lacks the chiral C1 atom and second ring of the former, resulting in an enhanced plasticity both at the local and global levels. aPvd2, the only analog sporting a double-ring chromophore, has similar spatial extents and undergoes little large-scale deformations ( $\mathrm{Rg})$, but is markedly more flexible at the local level (RMSD). aPvd3 is significantly more compact than the other pyoverdines and very rigid despite the absence of the second cycle and the larger number of carbon atoms between catecholate and peptide chain. Interactions within the siderophores obviously play an important role in amplifying or curbing the spatial extents and flexibility inherent to their respective chemical formulas. Decomposing each residue's contribution to conformational flexibility (see ESM) reveals the dynamics of Arg4 to be the most affected upon chromophore replacement. Indeed, its lengthy side chain and central position make it the perfect adjustment variable for adapting the peptide chain to different chelating group setups. In aPvd1 and aPvd2, Arg4 is located rather close to the metal center (Fig. 8 left panel), where repulsion between the charged guanidinium $\left(\mathrm{Gdm}^{+}\right)$and the metal occurs. This results in added plasticity for the arginine side chain (Fig. 8, center panel); however, the plane of the $\mathrm{Gdm}^{+}$group remains at all times orthogonal to the chromophore plane (Fig. 8, right panel), most likely because of transient stabilizing interactions between the chromophore $\pi$ electrons and $\mathrm{Gdm}^{+}$. This is in contrast with Pvdl, in which the 

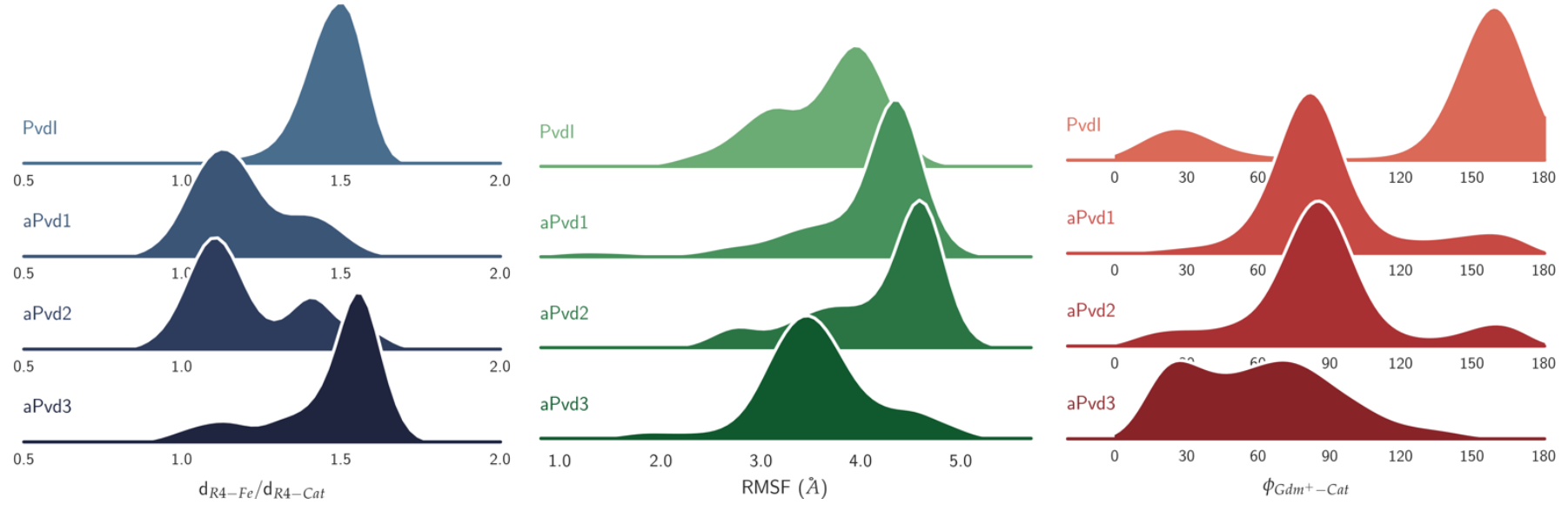

Fig. 8 Left: Distributions of (left) the ratio of the distance of $\operatorname{Arg} 4 \mathrm{C}_{\zeta}$ to Fe ${ }^{3+}$ over the distance of $\operatorname{Arg} 4 \mathrm{C}_{\zeta}$ to the catecholate center of mass; (center) the RMS fluctuations of Arg4 atoms; (right) the angle between the planes of the $\operatorname{Arg} 4$ guanidinium group $\left(\mathrm{Gdm}^{+}\right)$and the catecholate, for pyoverdine and its analogs

additional positive charge on the chromophore prevents such interactions and results in these planes being nearly stacked. In addition, the rigidity of the conjugated tri-cyclic scaffold keeps Arg4 further away from the metal center, where it is more accessible to other molecules - an important point since Arg4 plays a major role in the recognition of pyoverdine by itsmembrane transporter.[35] Through a combination of its amide scaffold, simultaneously longer and more rigid than those of the other analogs, aPvd3 achieves a much closer match with Pvdl with respect to the positioning and flexibility of Arg4. The effect of the Pvdl chromophore charge is partially emulated: although T-shaped $\mathrm{Gdm}^{+} /$chromophore conformations still exist, stacked conformations are now also encountered. Hence, both charge and conformational rigidity can be used to the same effect in fine-tuning the behavior of Arg4.

Recognition by the FpvA transporter. Docking calculations have been performed to predict whether or not the pyoverdine analogs interact with the FpvA transporter in the same way Pvdl does. In their seminal study on the binding of different pyoverdine strains to FpvA, Greenwald et al observed that the binding mode of the siderophore chelating groups onto FpvA was much more conserved across pyoverdine variants than that of the peptide chain, in line with the fact that the main variations between pyoverdine strands occur in the sequence of the peptide chain.[18] Notably, residue Arg204 of the transporter lid is brought in the vicinity of $\mathrm{Fe}^{3+}$ by a conformational transition of the corresponding loop upon binding of the siderophore to the transporter, while Val229 and Tyr231 make contact with the chromophore and the first hydroxamate. In our previous investigation, we showed that the specific recognition events involving the peptide chain mainly take place with the transporter lid loops during the phase leading to binding[35] Nevertheless, contacts can be observed in the bound state between Arg4 on the pyoverdine chain and residue Asp597 of the so-called L7 loop of the transporter, as well as with Asn228 via a transient hydrogen bond. We now examine whether these trends persist in our analogs.
The top-scoring docked structures of Pvdl, aPvd1, aPvd2 and aPvd3 are shown on Fig. 9. Reassuringly, the top scoring hit for the docking of Pvdl onto FpvA shows a near-perfect superimposition with the experimental structure and a score of $-10.5 \mathrm{kcal} \mathrm{mol}^{-1}$, quite close to our previous determination using a much more accurate methodology.[35] Although somewhat lower (-8.3, -9.3 and $-9.8 \mathrm{kcal}^{\text {. mol-1 }}{ }^{-1}$ for aPvd1, aPvd2 and aPvd3, respectively), the predicted affinities of our analogs for FpvA are compatible with efficient recognition and binding; however, the corresponding binding poses are quite different from that of Pvdl. For aPvd1, docked structures yield binding energies from 8.3 to $-6.2 \mathrm{kcal}^{\mathrm{mol}} \mathrm{m}^{-1}$ and the top-scoring structures is the closest to Pvdl. Since the metal center is shifted outwards and is somewhat more exposed to the solvent, the interactions between Arg204 and $\mathrm{Fe}^{3+}$ and between Asn228 and the backbone of Arg4 cannot take place; however, the interaction between Asp597 and Arg4 is preserved. For aPvd2, the binding energies fall within a -9.3 to $-6.4 \mathrm{kcal}^{\mathrm{mol}}{ }^{-1}$ range, but none of the docking solutions come close to the binding mode of Pvdl due to the very different relative orientation of the siderophores. The chelation center is exposed to the solvent and does not directly interact with any residue on FpvA; none of the aforementioned "canonical" interactions exist. Binding energies for aPvd3 vary between -9.8 and $-8.1 \mathrm{kcal}^{\mathrm{mol}}{ }^{-1}$. Although the global shape and volume of the top scoring structure are similar to those of $\mathrm{Pvdl}$, its position relative to FpvA is flipped just like aPvd2. The metallic center is oriented towards the extracellular side of the transporter, is exposed to the solvent and exhibits none of the previously mentioned metal/chromophore-FpvA interactions. However, looking at the lower-rank docking poses reveals the existence of a conformation of aPvd3 with an affinity of $-8.5 \mathrm{kcal} \mathrm{mol}^{-1}$, a low RMSD to the native Pvdl binding pose and which only lacks the interaction between Asn228 and the carbonyl of Arg4.

To conclude, aPvd1 and aPvd3 appear to have the ability to bind FpvA with conformations akin to that of native Pvdl and could presumably be recognized and internalized by the transporter, although the coexistence of other, very different binding modes raises a selectivity issue. 


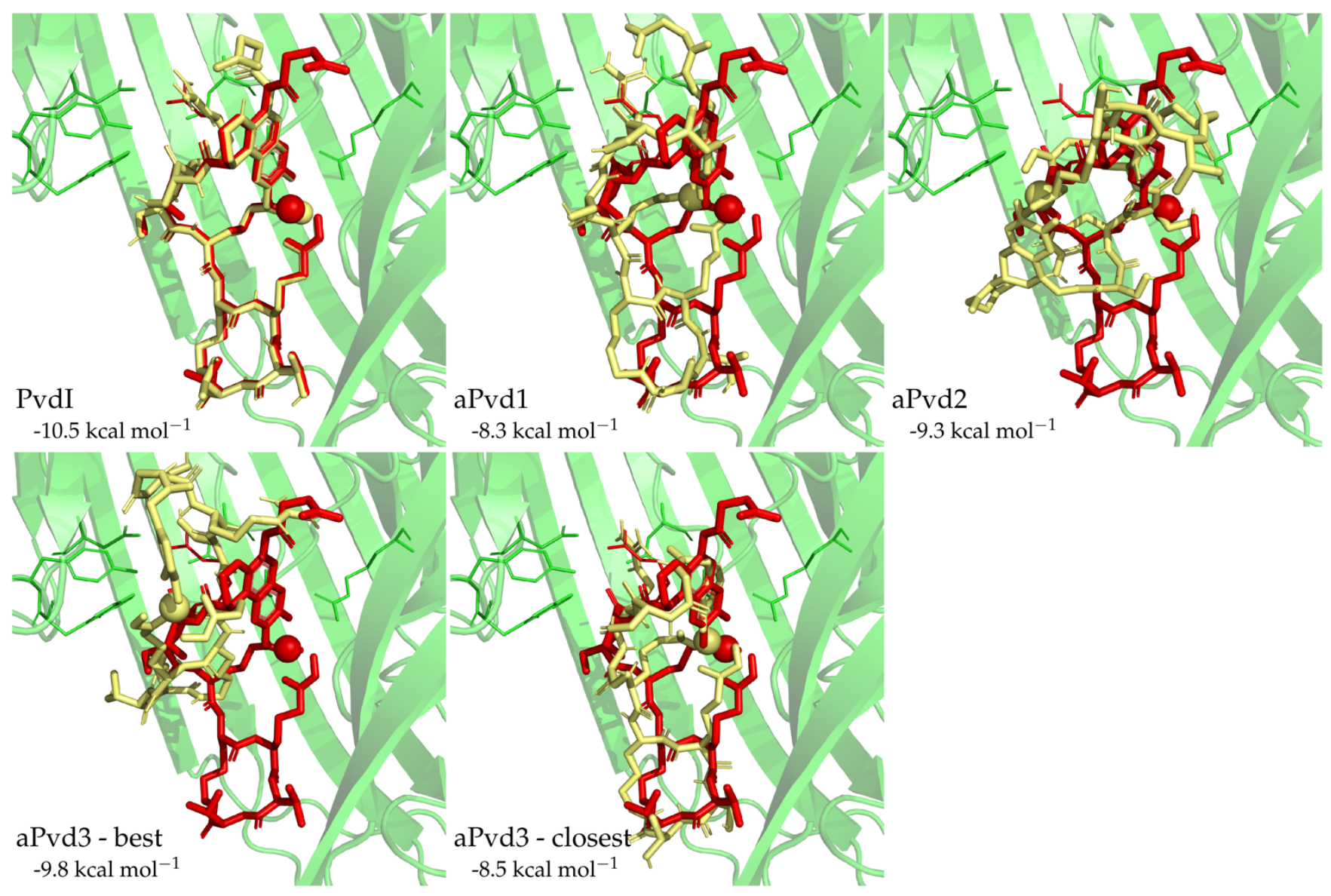

Fig. 9 Superimposition of the docking poses (labeled by their respective scores) of pyoverdine and analogs (yellow) onto the crystal structure of Pvdl (red) bound to FpvA (green cartoons, with aminoacid sidechains involved in pyoverdine recognition as green sticks). Unless otherwise specified, the top-ranking pose is shown

\section{Discussion}

The goal of this paper is the preliminary assessment, using molecular modeling methods, of relatively simple synthetic scaffolds able to mimic the pyoverdine chromophore in future antibacterial drugs based on the Trojan horse strategy. Thespecifications are fourfold: (i) chelation of iron with high affinity, (ii) recognition and binding by FpvA, (iii) propagation of the binding event signal through the outer membrane to the periplasm-located TonB subsystem which triggers the internalization and (iv) possibility of grafting antibiotic moieties without hindering recognition through unfavorable steric effects.

Metal ion binding affinities. Hay and coworkers have shown the affinity of tris-catecholamides for $\mathrm{Fe}^{3+}$ to be considerably diminished by deviations from the ideal chelating geometry due to steric strain.[63] $A b$ initio calculations on our analogs in the gas phase show a similar trend: overall, the replacement of the rigid and bulky native CRO- chromophore by the simpler and more flexible $\mathrm{CR}[1-3]^{2-}$ analogs allows shorter (hence stronger) iron-catecholate interactions. Although the additional negative charge on CR[1-3] ${ }^{2-}$ compared to CRO- slightly destabilizes hydroxamate-iron interactions via electronic repulsion, the overall balance remains in favor of our analogs. The cyclic peptide chain considerably enhances the effect by introducing an interdependence in the relative positions and orientations of the chelating groups, which the rigid $\mathrm{CRO}^{-}$is much less likely to compensate than the more flexible CR[1-3 $]^{2-}$ mimics. This effect has also been observed, on bacterial siderophores bacillibactin and enterobactin, by Dertz and coworkers.[64] Altogether, in the gas phase, the replacement of the native chromophore very clearly favors the metal-binding affinity.

Interestingly, when taking solvation into account, the picture is reversed: while the three proposed analogs can definitely chelate $\mathrm{Fe}^{3+}$ in an aqueous medium (as attested by the short and stable $\mathrm{Fe}^{3+}$... O distances seen in MD simulations despite the absence of bonded interactions), they do so with less affinity than Pvdl. In our previous work, [37] we have found a very good linear correlation between MM-GBSA binding free energies and experimental $\mathrm{pFe}$ values on similar pyoverdine analogs; applying this relationship to the binding free energies computed herein yields pFe values of 24 to 25 for all analogs under study, as compared to 27 for Pvdl. The superior affinity of Pvdl for iron arises from more favorable solvation electrostatic energies, linked to the better structuration of the water layers around the metal ion: the average number of water molecules in direct contact with $\mathrm{Fe}^{3+}$ is 8.80 and 8.88 in aPvd1 and aPvd2, vs. 9.23 in Pvdl. The interaction with water is obviously able to alleviate the incompatibilities between the preferred geometries of the 
peptide chain and metal-binding ligands observed in the gas phase. In our previous work, we had already concluded that the interaction of pyoverdine strains with water was more discriminating than their interactions with the FpvA transporter, and represented the dominant contribution to the binding free energy;[35] the same obviously holds true for the pFe of pyoverdines and analogs.

However, despite their lower affinity for $\mathrm{Fe}^{3+}$ than Pvdl, the predicted $\mathrm{pFe}$ values of our analogs remain quite high - similar to that of tris-hydroxamate desferrioxamine $B$, native siderophore of Streptomyces ( $\mathrm{pFe}=26.6)$ and much higher than the best analog considered in our previous study[37] $(p F e=21)$ despite the theoretically greater $\mathrm{Fe}^{3+}$ affinity of the latter's triscatecholate nature. aPvd1, aPvd2 and aPvd3 thus appear to meet the first of the criteria enumerated at the start of this section (which we will now strive to confirm experimentally).

Accommodating chelation electronics and conformational strain. The +1 charge borne by the native pyoverdine chromophore CRO- considerably complexifies the synthesis of analogs built thereupon. Hence, the evaluation of its relevance and purpose has been a key question from the onset of the study. Our $a b$ initio calculations have shown that, unlike the Cat ${ }^{2-}$ model ligand and its three mimics (CR12-, CR22- and CR32-), the properties of $\mathrm{CRO}^{-}$tend to change once integrated into a monocatecholate-bis-hydroxamate system. Despite the fact that $\mathrm{CRO}^{-}$chelates $\mathrm{Fe}^{3+}$ via its two $\mathrm{O}^{-}$atoms, the resulting interaction is dissymmetrical, with properties reminiscent of those observed upon complexation by a hydroxamate moiety: the $\mathrm{Fe}^{3+}\left(\mathrm{CRO}^{-}\right)\left(\mathrm{Aha}^{-}\right)_{2}$ system is closer to $\mathrm{Fe}^{3+}\left(\mathrm{Aha}^{-}\right)_{3}$ than $\mathrm{Fe}^{3+}\left(\mathrm{Cat}^{2-}\right)\left(\mathrm{Aha}^{-}\right)_{2}$, whereas $\mathrm{Fe}^{3+}\left(\mathrm{CRX}^{2-}\right)\left(\mathrm{Aha}^{-}\right)_{2}$ systems remain closer to the latter. This is in no small part due to the delocalization of the additional positive charge over the chromophore ring system, which affects the electrostatic and dispersive properties of the chromophore and weakens the $\mathrm{Fe}^{3+\ldots \mathrm{O}^{-}}$interactions by disrupting the electronic density at bond-critical points in a dissymmetrical way. The result is a ligand which combines the electronic effects of hydroxamate (lower iron binding affinities) with the additional bulk and rigidity of a substituted catecholate, limiting the conformational plasticity of the entire siderophore; this versatility is probably essential in the recognition and transport of the siderophore by the TonB machinery.

In aPvd1, aPvd2 and aPvd3, the conformational strain induced by the pyoverdine peptide chain on the placement of the chelating groups is also able to split the degeneracy of the catecholate $\mathrm{Fe}^{3+\ldots} \mathrm{O}$ bonds; however, they remain much stronger than hydroxamate- $\mathrm{Fe}^{3+}$ interactions, whereas Pvdl retains its striking similarity to a tris-hydroxamate siderophore. Part of the explanation for this discrepancy lies in the existence of an intramolecular interaction between CRO- and the $\mathrm{Gdm}^{+}$ group of Arg4 of the peptide chain. The positive charge on CRO limits the volume spanned by the $\mathrm{Gdm}^{+}$group and locks its position above the chromophore in a stacked conformation which rigidifies the peptide chain, helping to preserve relatively long (and weak) catecholate $\mathrm{Fe}^{3+\ldots O}$ bonds. This rigidity favors the structuration of hydration layers around the metal center, counterbalancing the entropic penalty with a stabilizing hydrogen bond network.

In aPvd1 and aPvd2, Arg4 interacts perpendicularly to the catecholate function and much closer to the metal center, limiting the ingress of water molecules and resulting in a weaker binding of $\mathrm{Fe}^{3+}$. Interestingly, aPvd3 comes the closest to mimicking the Arg4-chromophore interactions found in Pvdl, even though $\mathrm{CR}^{2-}$ appears the closest to $\mathrm{CRO}^{-}$both structurally and in terms of flexibility. This is most likely due to the combination of a compact yet rigid chromophore analog CR32and a longer linker length between catecholate and Arg4, which hinders the access of $\mathrm{Gdm}^{+}$to the vicinity of the metal center.

The combination of chromophore rigidity and added electronic charge thus marks Pvdl out as a "sweet spot" in the compromise between an efficient chelation environment and a favorable conformation of the peptide chain. However, the promising metal-binding affinity and solvent-ordering capacity of aPvd3 proves that the effect of the additional charge can be partly emulated via controlled steric effects.

The conundrum of transporter recognition specificity. Because iron is usually a very scarce resource, coexisting bacterial colonies are in constant competition to secure their requirements.[65] To gain the leading edge in this competition, bacteria would need to recognize and internalize siderophores from as many other bacterial strains as possible, while synthetizing highly specific native siderophores that as few as possible other bacterial strains can steal. These two antinomic statements place very high requirements on the recognition process by membrane transporters: recognizing native and "foreign" siderophores at the same site with the same mechanism is not possible unless both siderophores are quite similar, in which case the native siderophore is also easily recognized and "stolen" by other bacterial strains.

All pyoverdines recognized by FpvA (native or otherwise) chelate $\mathrm{Fe}^{3+}$ using chromophore $\mathrm{CRO}^{-}$and two hydroxamate residues; the position of the chromophore at the binding site and the interactions it forms with FpvA are conserved. This led Greenwald et al[18] to postulate that FpvA is specific for only one conformation of the iron-binding part of pyoverdine. Since then, however, couplings between the variable peptide chain and the immutable chromophore have come to light, revealing the complexity of the recognition patterns of membrane transporters such as FpvA and how little they are understood. For instance, we have previously shown that the peptide chain, which differs between pyoverdines in length, overall chemical character and cyclicity, impacts the position and conformational freedom of metal-binding moieties. [35] More recently, we have shown that FpvA can recognize and bind both $\Lambda$ - and $\Delta$-type stereoisomers of pyoverdines (defined based on the handedness of the octahedral arrangement of ligand arrangements around $\mathrm{Fe}^{3+}$ ) with a ratio of affinities that depends on the pyoverdine strain.[36] The docking calculations performed in this paper predict that, despite their rather different chemical natures, binding modes comparable to that of Pvdl exist for aPvd1 and aPvd3, with affinities which, albeit lower than that of the native siderophore, are comparable to 
those of other pyoverdine strains such as DSM50106 which are recognized by FpvA. [35] The compact size of aPvd3 accounts for the coexistence of several poses within a small energy range, raising possible selectivity issues; however, this behavior is also seen (to a lesser degree) for the native siderophore and is probably alleviated by the conformational selection which takes place during the first stages of the recognition by FpvA. [35] This compactness also opens the possibility of grafting additional antibiotic moieties to aPvd3 while still fitting in the FpvA binding pocket, an important feature for a Trojan horse scaffold.

Considering Arg4's importance in the recognition and binding of pyoverdines by FpvA, the similarity of this residue's conformational behavior in aPvd3 and Pvdl is promising. In some siderophores, cationic aminoacids with long sidechains such as Lys or Arg have been shown to efficiently displace structured water layers and hydrated ions from interfaces, preconditioning them for binding.[66-68] Indeed, we previously observed a similar mechanism for the binding of Pvdl to FpvA,[35] and the evidence gathered from this work suggest that aPvd3 should also be concerned. In addition, based on our finding that the position of Arg4 is strongly influenced by the additional positive charge on $\mathrm{CRO}^{-}$, we suggest that Arg4 (or a similarly placed positively charged residue) could act as a vanguard for the chromophore's positive charge, allowing the indirect recognition of this feature by FpvA during the initial phase of the binding process; mimicking the conformational properties of Arg 4 could possibly favor recognition even in the absence of this additional charge. Finally, the absence in our analogs of the two simultaneous contacts between Arg4 and the transporter observed in Pvdl (at the Gdm+ extremity via Asp597 and at the backbone via Asn228) does not necessarily raise issues: both aPvd1 and aPvd3 retain the contact to the transporter L7 loop via Asp597 also seen in non-native pyoverdines, known to be transported by FpvA, featuring different (positively charged) residues at position 4. [18]

\section{Concluding remarks}

In this work, we provide evidence that while the positive charge and the rigidity of the chromophore scaffold are crucial both for the binding of iron and the recognition by FpvA, their effects can be effectively emulated using other chemical functions. Indeed, our calculations predict pyoverdine analog aPvd3 to be a promising candidate on both accounts simultaneously. The experimental validation of these results and the optimization of this "lead" scaffold, much more amenable to synthesis than the native pyoverdine chromophore, are the next logical steps in our investigation. However, it should be kept in mind that pyoverdine fulfills many more roles than just scavenging iron (as an example, it regulates the expression of at least three virulence factors.[69, 70]) The impact of our analogs on these additional functions is, naturally, beyond the scope of this limited study. Nevertheless, through the latter, we hope to convey the message that the same structural and conformational polymorphism which powers such a broad array of simultaneous functions also offers great potential for the future design of pyoverdine mimics for therapeutic purposes.
Acknowledgements The authors thank Région Picardie for financial support (SIDERBACT grant - Projets Régionaux Structurants 2011). The calculations presented in this work were performed using HPC resources from the MATRICS computing platform of Université de Picardie Jules Verne.

\section{References}

1. Zilberberg MD, Shorr AF (2013) J. Hosp. Med. 8:559-563.

2. Croughs PD, Li B, Hoogkamp-Korstanje JA, Stobberingh E, Antibiotic Resistance Surveillance G (2013) Eur. J. Clin. Microbiol. Infect. Dis. 32:283-288.

3. Sievert DM, Ricks P, Edwards JR, Schneider A, Patel J, Srinivasan A, Kallen A, Limbago B, Fridkin S, National Healthcare Safety Network T, Participating NF (2013) Infect. Control. Hosp. Epidemiol. 34:1-14.

4. Nations U. Draft political declara-tion of the high-level meeting of the General Assembly on antimicrobial resistance. 2016; Available from: http:// www.un.org/pga/71/wp-content/uploads/ sites/40/2016/09/DGACM_GAEAD_ ESCAB-AMR-Draft-Political-Declaration- 1616108E.pdf.

5. Brickner SJ, Barbachyn MR, Hutchinson DK, Manninen PR (2008) J. Med. Chem. 51:1981-1990.

6. Czaplewski L, Bax R, Clokie M, Dawson M, Fairhead H, Fischetti VA, Foster S, Gilmore BF, Hancock RE, Harper D, Henderson IR, Hilpert K, Jones BV, Kadioglu A, Knowles D, Olafsdottir S, Payne D, Projan S, Shaunak S, Silverman J, Thomas CM, Trust TJ, Warn P, Rex JH (2016) Lancet Infect. Dis. 16:239-251.

7. de la Fuente-Nunez C, Reffuveille F, Fernandez L, Hancock RE (2013) Curr. Opin. Microbiol. 16:580-589.

8. de la Fuente-Nunez C, Reffuveille F, Haney EF, Straus SK, Hancock RE (2014) PLoS Pathog. 10:e1004152.

9. Li XZ, Ma D, Livermore DM, Nikaido H (1994) Antimicrob. Agents Chemother. 38:1742-1752.

10. Poole K, Srikumar R (2001) Curr. Top. Med. Chem. 1:31-57.

11. Zgurskaya HI, Lopez CA, Gnanakaran S (2015) ACS Infect. Dis. 1:512-522.

12. Munita JM, Arias CA (2016) Microbiol. Spectr. 4:VMBF0016-2015.

13. Chandrangsu P, Rensing C, Helmann JD (2017) Nat. Rev. Microbiol. 15:338-350.

14. Dumas Z, Ross-Gillespie A, Kummerli R (2013) Proc. Biol. Sci. 280:20131055.

15. Zheng T, Nolan EM (2012) Metallomics 4:866-880.

16. Hider RC, Kong X (2010) Nat. Prod. Rep. 27:637-657.

17. Brandel J, Humbert N, Elhabiri M, Schalk IJ, Mislin GL, Albrecht-Gary AM (2012) Dalton Trans. 41:2820-2834.

18. Greenwald J, Nader M, Celia H, Gruffaz C, Geoffroy V, Meyer JM, Schalk IJ, Pattus F (2009) Mol. Microbiol. 72:1246-1259.

19. White $P$, Joshi A, Rassam P, Housden NG, Kaminska R, Goult JD, Redfield C, McCaughey LC, Walker D, Mohammed S, Kleanthous C (2017) Proc Natl Acad Sci U S A 114:1205112056.

20. Budzikiewicz H (2001) Curr. Top. Med. Chem. 1:73-82.

21. Ghosh M, Miller MJ (1996) Bioorg. Med. Chem. 4:43-48.

22. Mies KA, Gebhardt P, Mollmann U, Crumbliss AL (2008) J Inorg Biochem 102:850-861.

23. Mislin GL, Schalk IJ (2014) Metallomics 6:408-420. 

Antibiot. 51:499-507. Szebesczyk A, Olshvang E, Shanzer A, Carver PL, GumiennaKontecka E (2016) Coord. Chem. Rev. 327-328:84-109. Pletzer D, Mansour SC, Wuerth K, Rahanjam N, Hancock RE (2017) mBio 8:

28. Post SJ, Shapiro JA, Wuest WM (2019) MedChemComm 10:505-512.

29. Marvig RL, Damkiaer S, Khademi SM, Markussen TM, Molin S, Jelsbak L (2014) mBio 5:e00966-00914.

30. de Carvalho CC, Fernandes P (2014) Front. Microbiol. $5: 290$. Jordan EO (1899) Bot. Gaz. 27:19-36.

32. Teintze $\mathrm{M}$, Hossain $\mathrm{MB}$, Barnes $\mathrm{CL}$, Leong $\mathrm{J}$, van der Helm $\mathrm{D}$ (1981) Biochemistry 20:6446-6457.

33. Budzikiewicz H (2004) Fortschr. Chem. Org. Naturst. 87:81237.

34. Meyer JM, Gruffaz C, Raharinosy V, Bezverbnaya I, Schafer M, Budzikiewicz H (2008) Biometals 21:259-271.

35. Bouvier B, Cezard C, Sonnet P (2015) Phys. Chem. Chem. Phys. 17:18022-18034.

36. Bouvier B, Cezard C (2017) Phys. Chem. Chem. Phys. 19:29498-29507.

Antonietti V, Boudesocque S, Dupont L, Farvacques N, Cezard C, Da Nascimento S, Raimbert JF, Socrier L, Robin TJ, Morandat S, El Kirat K, Mullie C, Sonnet P (2017) Eur. J. Med. Chem. 137:338-350.

38. Becke AD (1988) Phys. Rev. A 38:3098-3100. Becke AD (1993) J. Chem. Phys. 98:5648-5652.

Lee C, Yang W, Parr RG (1988) Phys. Rev. B Condens. Matter 37:785-789.

41. Zhao Y, Truhlar DG (2008) Acc. Chem. Res. 41:157-167.

42. Zhao Y, Truhlar DG (2008) Ther. Chem. Acc. 120:215-241.

43. Hirao H, Thellamurege N, Zhang X (2014) Front. Chem. 2:14.

44. Kepp KP (2013) Coord. Chem. Rev. 257:196-209.

45. Verma P, Varga Z, Klein JEMN, Cramer CJ, Que L, Truhlar DG (2017) Phys. Chem. Chem. Phys. 19:13049-13069.

46. Domagal-Goldman SD, Paul KW, Sparks DL, Kubicki JD (2009) Geochim Cosmochim Acta. 73:1-12.

47. Liu Q, Lu X, Li L, Zhang H, Liu G, Zhong H, Zeng H (2016) J. Phys. Chem. C 120:21670-21677.

48. Moreno M, Zacarias A, Porzel A, Velasquez L, Gonzalez G, Alegria-Arcos M, Gonzalez-Nilo F, Gross EKU (2018) Spectrochim Acta A Mol Biomol Spectrosc 198:264-277.

49. Kaviani S, Izadyar M, Housaindokht MR (2017) Comput. Biol. Chem. 67:114-121.

50. Matin MA, Chitumalla RK, Lim M, Gao X, Jang J (2015) J. Phys. Chem. B 119:5496-5504.

51. Matin M, Islam M, Bredow T, Aziz M (2017) Adv. Chem. Engineer. Sci. 7:137-153.

52. Bader RFW, Atoms in Molecules, A Quantum Theory, ed. O.U. Press. 1994, USA.

53. Matta CF, Boyd RJ, An Introduction to the Quantum Theory of Atoms in Molecules, in The Quantum Theory of Atoms in Molecules, C.F.M.a.R.J. Boyd, Editor. 2007. p. 1-34.

54. Hornak V, Abel R, Okur A, Strockbine B, Roitberg A, Simmerling C (2006) Proteins 65:712-725.

55. Giammona DA, PhD thesis. 1984, University of California: Davis.
Essmann U, Perera L, Berkowitz ML, Darden TA, Lee $\mathrm{H}$, Pedersen LG (1995) J. Chem. Phys. 103:8577-8593.

57. Liu Y, Liu Y, Drew MGB (2014) Coord. Chem. Rev. 260:3764.

58. Mashiach R, Meijler MM (2013) Org. Lett. 15:1702-1705.

59. Wang $X$, Liu C, Zeng X, Wang X, Wang X, Hu Y (2017) Org. Lett. 19:3378-3381.

60. Shanzer A, Libman J, Lifson S, Felder CE (1986) J. Am. Chem. Soc. 108:7609-7619.

61. Boukhalfa H, Crumbliss AL (2002) Biometals 15:325-339.

62. Raymond KN, Isied SS, Brown LD, Fronczek FR, Nibert JH (1976) J. Am. Chem. Soc. 98:1767-1774.

63. Hay BP, Dixon DA, Vargas R, Garza J, Raymond KN (2001) Inorg. Chem. 40:3922-3935.

64. Dertz EA, Xu J, Stintzi A, Raymond KN (2006) J. Am. Chem. Soc. 128:22-23.

65.

Griffin AS, West SA, Buckling A (2004) Nature 430:10241027.

66. Rapp MV, Maier GP, Dobbs HA, Higdon NJ, Waite JH, Butler A, Israelachvili JN (2016) J. Am. Chem. Soc. 138:9013-9016. Maier GP, Butler A (2017) J. Biol. Inorg. Chem. 22:739-749.

68. Li Y, Wang T, Xia L, Wang L, Qin M, Li Y, Wang W, Cao Y (2017) J. Mater. Chem. B 5:4416-4420.

69. Ravel J, Cornelis P (2003) Trends Microbiol. 11:195-200.

70. Lamont IL, Beare PA, Ochsner U, Vasil Al, Vasil ML (2002) Proc. Natl. Acad. Sci. USA 99:7072-7077. 